DOI: $10.1515 /$ pts-2016-0036

SOLID STATE PHYSICS

\title{
USE OF COMPUTER-GENERATED HOLOGRAMS IN SECURITY HOLOGRAM APPLICATIONS
}

\author{
A. Bulanovs ${ }^{1}$, R. Bakanas ${ }^{2,3}$ \\ ${ }^{1}$ Innovative Microscopy Centre, Daugavpils University, \\ 1 Parades Str., Daugavpils, LATVIA \\ ${ }^{2}$ Geola Digital UAB, Vilnius, LITHUANIA \\ ${ }^{3}$ Department of Materials Engineering, Kaunas University of Technology, \\ Kaunas, LITHUANIA \\ E-mail: bulanov@inbox.lv
}

\begin{abstract}
The article discusses the use of computer-generated holograms (CGHs) for the application as one of the security features in the relief-phase protective holograms. An improved method of calculating CGHs is presented, based on ray-tracing approach in the case of interference of parallel rays.

Software is developed for the calculation of multilevel phase CGHs and their integration in the application of security holograms. Topology of calculated computer-generated phase holograms was recorded on the photoresist by the optical greyscale lithography. Parameters of the recorded microstructures were investigated with the help of the atomic-force microscopy (AFM) and scanning electron microscopy (SEM) methods. The results of the research have shown highly protective properties of the security elements based on $\mathrm{CGH}$ microstructures. In our opinion, a wide use of CGHs is very promising in the structure of complex security holograms for increasing the level of protection against counterfeit.
\end{abstract}

Keywords: diffractive optical elements, digital holography, protective holograms.

\section{INTRODUCTION}

Relief-phase holograms are widely used in most security applications such as credit cards and passports. They are suitable for the emboss replication process and are easily mass-produced at a low cost. Holograms are applied to documents or products, and the presence of a hologram is intended to be a reliable indication that the document or product is valid. Modern relief-phase holograms contain a wide range of security and visual effects to make them hard to copy or counterfeit. The present article reviews some additional security effects based on the computer-generated ho- 
lograms (CGHs) that can be integrated in the structure of protective holograms. It is commonly considered that a $\mathrm{CGH}$ is a result of optical recording of the interference field, which was calculated within a diffraction theory with the help of a computer. The receiving topology of CGHs requires a huge amount of calculation and it is a challenge even for modern computers [1]. Therefore, only simple flat objects can be used for calculation to make it in reasonable time. There are several digital technologies suitable for recording of $\mathrm{CHG}$ interference images on the photoresist. The most widely spread ones are the interference optical lithography [2], [3] (the so-called "image-matrix" technology) and e-beam lithography [4].

\section{THEORETICAL BACKGROUND}

Let us consider calculation of a CGH in the case that is most important for practical use, i.e., reconstruction of a hologram image in parallel rays. In this case, with a laser beam falling on the surface of a hologram, the original image is restored in any plane parallel to the hologram surface. The size of the reconstructed image becomes bigger in proportion to the increase of the distance between the observation plane (frosted screen) and the hologram. In practice, it is convenient to use a greyscale bitmap image as an original one. A relative brightness of dots in the reconstructed image, then, is defined as $K_{a}=\frac{G_{a}}{255}$, where $G_{a}=[0 . .255]$ is a level of the grey colour of the corresponding pixels in the graphic image. Thus, $K_{a}=1$ is for white pixels of the bitmap image, to which the dots with maximal brightness in the reconstructed hologram image correspond. $K_{a}=0$ is for black pixels of the bitmap image for which there is no correspondence in the hologram (dots with zero brightness).

The aim of the theoretical part of this paper is to demonstrate how a required change in phase for the reflected wave can be calculated for each $B$ segment in the hologram (Fig. 1). Given local changes of the reflected wave front, it is easy to calculate the required micro relief topology of the hologram surface. Thus, the maximal depth of the hologram relief $\Delta h=\frac{\lambda}{2}$ corresponds to the change of the phase by $\Delta \varphi=2 \pi$. As far as intermediary values $\Delta \varphi$ are concerned, the relief depth is proportionate to the phase:

$$
\Delta h=\frac{\lambda}{4 \pi} \Delta \varphi
$$

where $\lambda$ is length of the wave for which the CGH is calculated.

Let us assume that the original flat image consists of the finite number of dots and is formed in plane $\psi$ (Fig. 1), which is parallel to the hologram surface and is situated at the distance $Z$ from it. Let us now find the result of interference of all flat waves passing through active dots of the image to the centre of a $\mathrm{CGH}$.

For one of the image dots, $A=\left(X_{a}, Y_{a}, Z\right)$ (Fig. 1), this direction is vector $\overrightarrow{O A}$, and plane $\Omega_{a}$ corresponds to the wave front surface passing through the hologram centre $O$ (Fig. 1). 


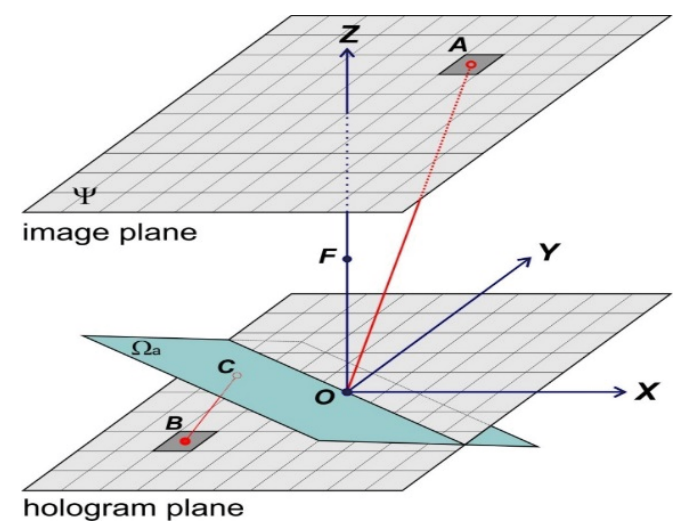

Fig. 1. Sketch for explaining CGH calculation.

Then $\overrightarrow{n_{a}}=\frac{\overrightarrow{O A}}{|\overrightarrow{O A}|}=\left(\frac{X_{a}}{L_{a}}, \frac{Y_{a}}{L_{a}}, \frac{Z}{L_{a}}\right)$, where $L_{a}=\sqrt{X_{a}^{2}+Y_{a}^{2}+Z^{2}}$ will be a unit vector of the normal line to plane $\Omega_{a}$. $[0 . .2 \pi]$.

Phase $\psi_{a}$ of wave front $\Omega_{a}$ has an unspecified arbitrary value in the range

The distance from dot $B=\left(X_{b}, Y_{b}, 0\right)$ of the hologram to plane $\Omega_{a}$

$$
S_{a}=B C=\left(\overrightarrow{O B} \cdot \overrightarrow{n_{a}}\right)=\frac{X_{b} X_{a}}{L_{a}}+\frac{Y_{b} Y_{a}}{L_{a}} \text {, where } \overrightarrow{O B}=\left(X_{b}, Y_{b}, 0\right)
$$

Taking into account (2), the phase of flat wave in $\operatorname{dot} B$ from source $A$ is

$$
\varphi_{a}=\frac{2 \pi}{\lambda} S_{a}+\psi_{a}=\frac{2 \pi}{\lambda L_{a}}\left(X_{b} X_{a}+Y_{b} Y_{a}\right)+\psi_{a}
$$

Complete complex amplitude of interference field in $\operatorname{dot} B$ is determined by the sum total of complex amplitudes of the object waves from all elemental sources of the original image and reference wave:

$$
\dot{A_{b}}=\sum_{a} A_{0} K_{a} e^{-i \varphi_{a}}=A_{0} \sum_{a} K_{a} e^{-i \varphi_{a}}
$$

Flat wave front that is parallel to the hologram surface was appointed as a reference wave. In (3), the additive component, similar to the one in $\operatorname{dot}(0,0, \mathrm{Z})$ of the image, corresponds to the reference wave. Amplitudes of object waves $A_{0} K_{a}$ are proportional to the brightness of corresponding graphic dots. Formula (4) allows for determining the required change of phase in all dots $B$ of the hologram for reconstructing a diffractive image:

$$
\varphi_{b}=\tan ^{-1}\left(\frac{\operatorname{Im}\left(\dot{A}_{b}\right)}{\operatorname{Re}\left(\dot{A}_{b}\right)}\right)=\tan ^{-1}\left(\frac{\sum_{a} K_{a} \sin \left(\varphi_{a}\right)}{\sum_{a} K_{a} \cos \left(\varphi_{a}\right)}\right), \quad \varphi_{b} \in[0 . .2 \pi)
$$


In case of protective holograms, phase modulation of the reflected wave, in accordance with (5), is defined by the micro relief height of the hologram surface following (1). The image of the CGH object will be reconstructed in the parallel rays; the process can be observed only with the help of a frosted screen or a specially selected lens. For direct observation of the reconstructed object, it is necessary to add the phase function of a lens to the phase surface of the hologram (5). A complete phase of the hologram sector in $\operatorname{dot} B$ will then be:

$$
\phi_{b}=\varphi_{b}+\varepsilon_{b}, \text { where } \varepsilon_{b} \text { is a lens phase function. }
$$

Let us find $\varepsilon_{b}$ for a thin lens with the focus in dot $\mathrm{F}$ and focal distance $F=\mathrm{OF}$ (Fig. 1). An optical difference between the travels of beams for a virtual lens in dot $B$ will be:

$$
\Delta l_{b}=n\left(\sqrt{F^{2}+X_{b}^{2}+Y_{b}^{2}}-F\right) \approx n \frac{X_{b}^{2}+Y_{b}^{2}}{2 F},
$$

where $n \approx 1.5$ is a refractive index of the virtual lens material. The phase surface of the flat wave after passing though the virtual lens is:

$$
\varepsilon_{b}=\frac{2 \pi}{\lambda} \Delta l_{b}=\frac{\pi n}{\lambda F}\left(X_{b}^{2}+Y_{b}^{2}\right)
$$

In (7), value $\varepsilon_{b}$ corresponds to a negative lens, and magnitude $-\varepsilon_{b}$ indicates a collecting lens. If CGH is calculated following (6), only a remote point light source is necessary for observing of the reconstructed image. A spherical wave from the remote point source of light within the rage of a linear size of CGH can be considered flat with a high degree of precision. Since the calculation of $\mathrm{CGH}$ is carried out for a particular wavelength, observation of a CGH with the help of a lamp or the sun will yield a reconstructed image that is blurred and coloured due to spectral selectivity of $\mathrm{CGH}$.

\section{EXPERIMENTAL PART}

A special computer program was developed for calculating CGHs. For this purpose, an 8-bit greyscale bitmap image was used as a flat object for CGH calculation. The dots of grey scale level define relative brightness of the reconstructed image. The maximal size of the original graphic file is 150x150 pixels. For recording on the photoresist with the resolution of $12500 \mathrm{dpi}$, a discretisation spacing was chosen as $\mathrm{d}=2 \mathrm{um}$. The maximal diffraction angle with this resolution equals $\alpha=\frac{\lambda}{2 \mathrm{~d}}=0.15$ for $\lambda=600 \mathrm{~nm}$. With these parameters of calculating a $\mathrm{CGH}$, the reconstructed image is approximately $30 \mathrm{~mm}$ in size at the distance of $100 \mathrm{~mm}$ from the hologram surface.

The discretisation spacing of the original image was chosen equal to $30 / \mathrm{N}$ $\mathrm{mm}(\mathrm{N}$ is maximal size of the bitmap image in pixels), which corresponded to the 
distance of $100 \mathrm{~mm}$ between the hologram and the plane of observing the image. The results of calculating of a CGH according to (5) and (6) were recorded in a file compatible with the format of the files for the DifX optical lithography device aimed at recording of protective holograms [5], [6]. During the optical recording of a CGH, information about the phase of the current dots is extracted from the file, and the image is calculated for displaying on the SLM and further projection on the photoresist. One cycle of calculating of an image of the size 1920x1080 pixels for the Spatial Light Modulator (SLM) takes about 100 ms. Figure 2 shows part of the image calculated for displaying on the SLM.
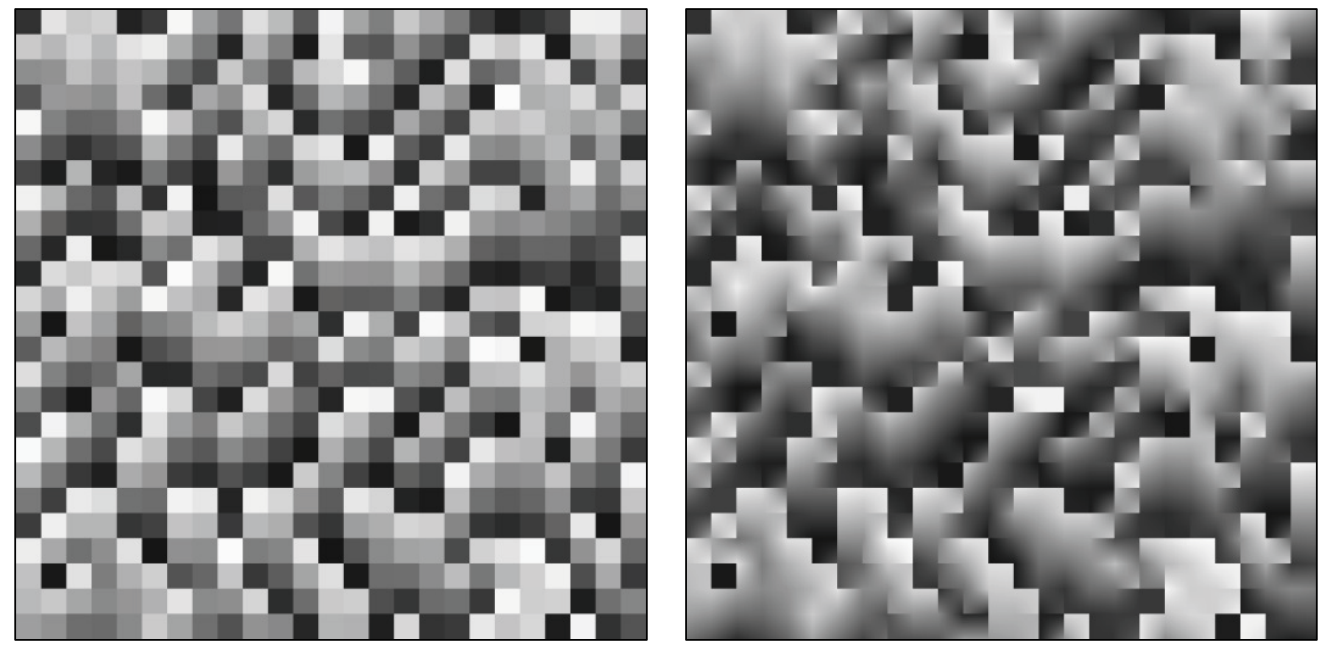

Fig. 2. Part of the CGH bitmap image calculated by the software.

a) Initial image after calculation.

b) Calculated image after approximation procedure.

In Fig. 2a, the program of the optical recording device is getting the image ready for recording of the section of a CGH directly according to the calculation data from the file. In Fig. 2b, an approximation option is used for calculating intermediary values in the framework of every discrete sector of a $\mathrm{CGH}$ while preparing the image for displaying on the SLM.

For recording of a CGH on the photoresist, a commercially available system for optical lithography DifX [6] was used. A simplified sketch of the optical scheme for $\mathrm{CGH}$ recording is shown in Fig. 3a. $S$-polarized laser beam $\mathbf{1}$ is directed by the polarising beam splitter 3 on the LCOS [7] (Liquid Crystal on Silicon) modulator 2. When there is no signal (black coloured pixels), the polarization plane of the light reflected from the LCOS SLM does not change, and the laser beam is directed by the beam splitter 3 in the initial direction 1. When the colour of pixels changes, the polarization plane of the light reflected from the SLM turns, and part of the radiation with $P$-polarization passes through the beam splitter 3 in the direction of focusing optics $\mathbf{4}$ and is projected on the photoresist $\mathbf{5}$. 
An important precondition of recording of qualitative relief-phase CGHs is a precise linear and proportional correspondence between the level of the grey colour in the image calculated for the SLM and the corresponding depth of the relief on the photoresist.

At the first stage of preparation to recording, a linear working range of the LCOS modulator was determined. A calibration schedule of the dependence of laser radiation intensity in the photoresist plane on the level of the grey colour of the image (Fig. 3b) was obtained experimentally. In course of experiment, an evenly coloured image with 8-bit greyscale value in the range [0..255] was displayed on the modulator. For each grey colour value, intensity of radiation in the recording place was measured. Figure $3 \mathrm{~b}$ shows a calibration scale for LCOS SLM, with the use of the manufactured tuning controls.

a)

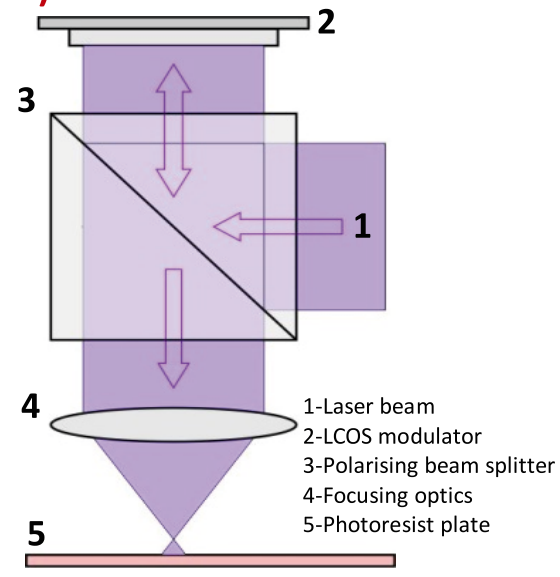

b)

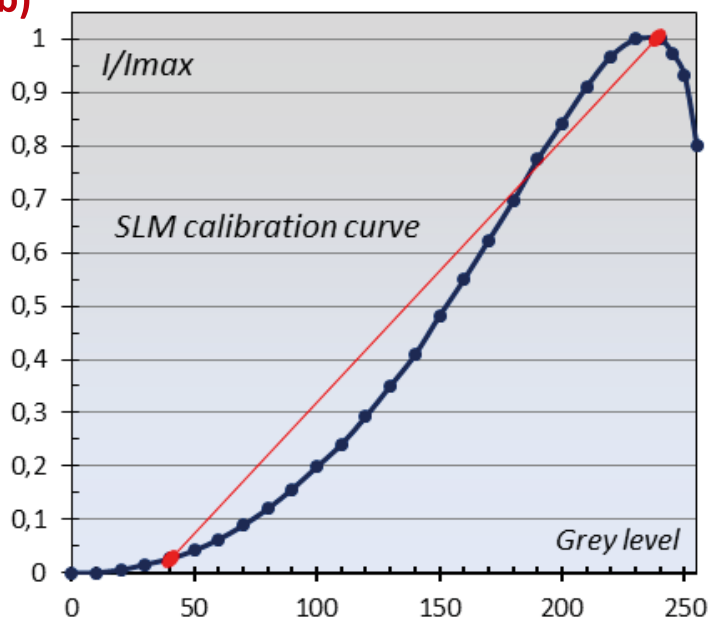

Fig. 3. a) Sketch of the optical scheme for CGH recording.

b) Calibration curve for multilevel $\mathrm{CGH}$ recording.

It is worth mentioning that a calibration curve may be adjusted with the help of parameter controls of the modulator drivers. In our case, though, this was not done because of the influence of the changed controls on other work modes of the optical lithography device.

A greyscale range of 40-230 was selected as a linear working range for optical recording (red line, Fig. 3b). The linear interdependence between the grey colour level and exposition is satisfactorily realised in this selected range. At the second stage of the adjustment of optical recording, an optimal exposition was determined; with it, the depth of the relief on the photoresist corresponded to the calculated value (1). For this purpose, an image of lines coloured with the gradient of the grey colour change (Fig. 4a) was projected on the photoresist from the modulator. 

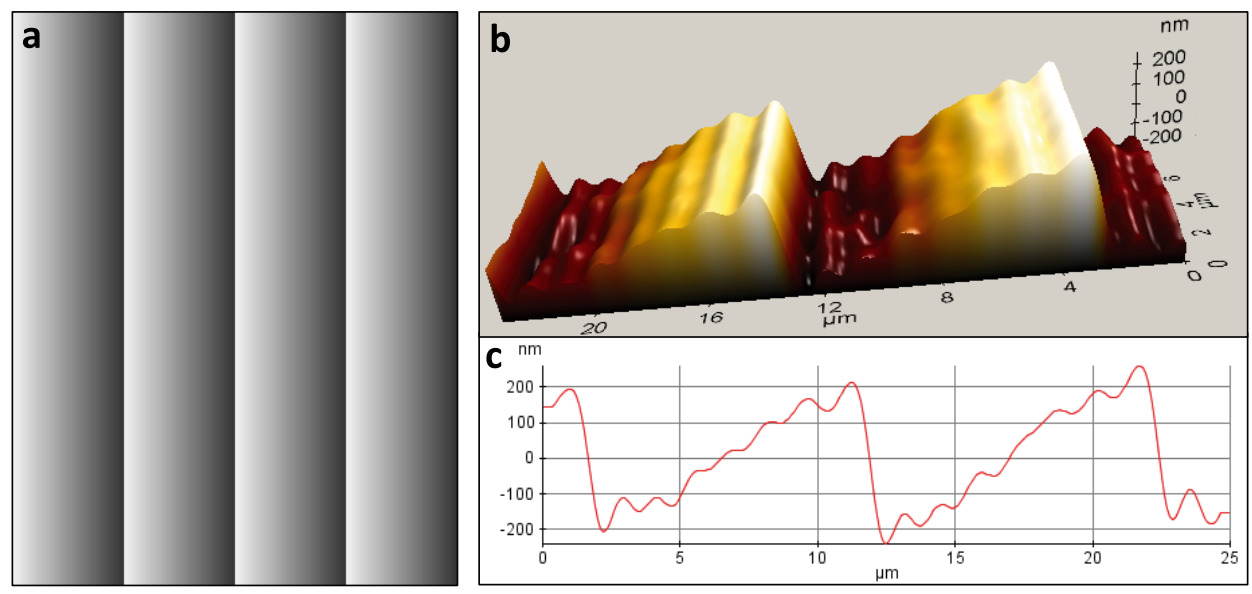

Fig. 4. a) Part of calibrated image for sawtooth grating recording.

b) AFM image of recorded sawtooth grating.

c) Profile of recorded sawtooth grating.

The range of colour change corresponded to a linear segment of the SLM calibration curve. The width of the lines after projection on the photoresist was $10 \mathrm{um}$, a test exposure dose was $20 \mathrm{~mJ} / \mathrm{cm}^{2}$. We used the photoresist AZ1514H [8] for recording; it was deposited on the glass substrate of the size $5 \times 5$ inch by the spin coating method. The photoresist layer was about 2 um thick. Development of the exposed plates was performed by the water solution of the concentrate AZ303 in the 1:4 proportions during $10 \mathrm{sec}$ at $20^{\circ} \mathrm{C}$. A linear dependence of the development speed on exposition was expected. An AFM (Park Systems NX10) was used to analyse relief and profile of the obtained diffraction gratings. On the basis of the obtained data (Fig. $4 \mathrm{~b}, \mathrm{c}$ ), an optimal exposition $12 \mathrm{~mJ} / \mathrm{cm}^{2}$ was chosen for recording of a CGH with the $300 \mathrm{~nm}$ relief depth. Using optimal parameters of optical recording, test samples of CGH calculated using (5) and (6) were produced.

\section{RESULTS AND DISCUSSION}

A bitmap image of size 100x100 dots was used to calculate CGHs. Approximate calculation time of CGH of 5000x5000 pixels was 5 min for the "hidden image" effect [9] (Fig. 4a, b) and around 15 min for the "image in lens" effect (Fig. 4c). With the discretisation spacing equal to $2 \mathrm{um}$, the size of $\mathrm{CGH}$ of $5000 \times 5000$ pixels was $1 \mathrm{~cm}^{2}(10 \times 10 \mathrm{~mm})$ on the photoresist; optical recording of samples took around 30 min (recording speed was about $2 \mathrm{~cm}^{2}$ /hour). After recording and development procedures, surface topology of the samples was investigated with the help of scanning electron microscopy (SEM). Figure 3a shows a surface segment of 80x80um of a relief-phase digital hologram. This segment contains $40 \times 40=1600$ calculated pixels. Figure $3 \mathrm{~b}$ presents an AFM image of a part of the same hologram, showing that the relief height of the hologram surface remains within the required calculated range of 0-300um. 

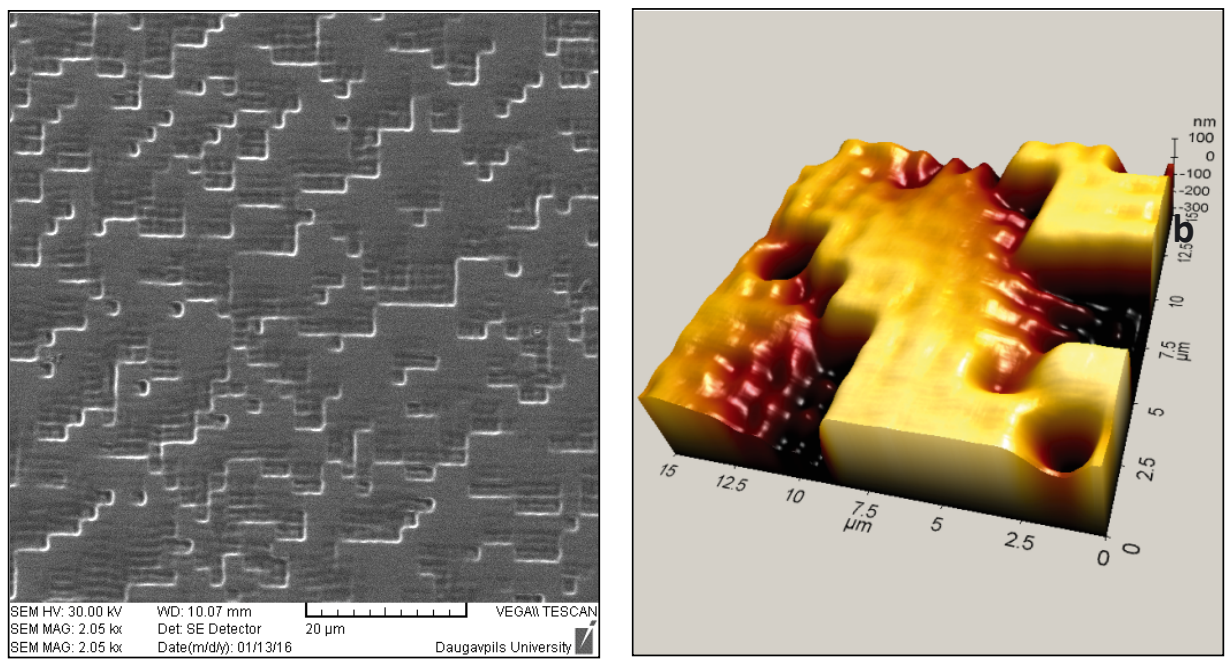

Fig. 3. a) SEM image of photoresist surface with a CGH element.

b) AFM image of photoresist surface with a CGH element.
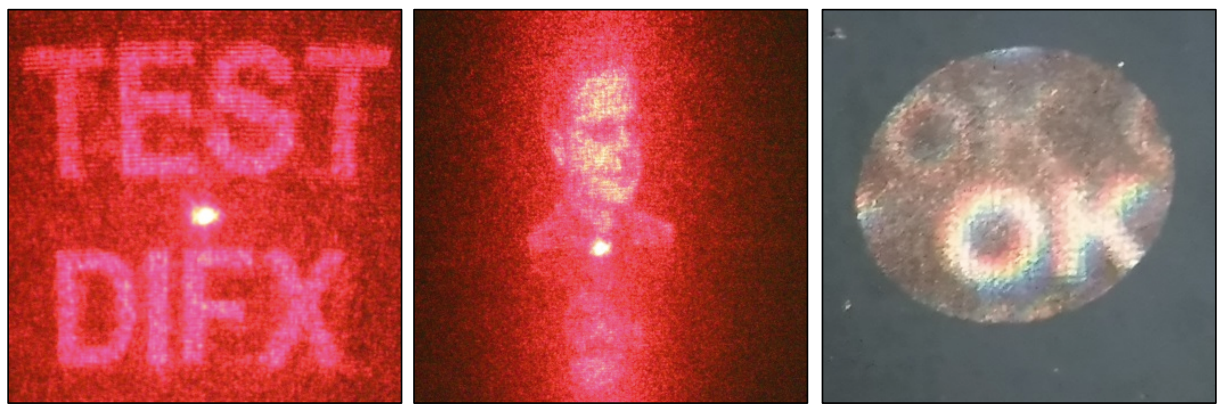

Fig. 4. a), b) Photos of the image recovered from the "hidden image" CGH on a scattering screen. c) Photo of the photoresist surface with the "text in lens" CGH element.

Figure $4 \mathrm{a}, \mathrm{b}$ demonstrates photos of the image recovered from a "hidden image" CGH on a scattering screen. A photo of the photoresist surface with the "text in lens" CGH element, which was made under a point like light source, is shown in Fig. 4c. After optical recording and development, CGH samples were coated with a $\sim 10-15 \mathrm{~nm}$ layer of silver with the help of a vacuum deposition method (reflection about $95 \%$ ). The reconstructed image was formed by a laser beam reflected from the CGH surface on the scattering flat screen. For diffraction efficiency (DE) evaluation of CGH samples, the following formula was used:

$$
D E=100 \% \cdot \frac{I_{0}-I}{I_{0}}
$$

where $I_{0}$ is intensity of the laser beam falling on a $\mathrm{CGH}$, and $I$ is intensity of the zero order diffraction in the reflected beam. The measured DE in the obtained samples of CGH was within the range of $80-85 \%$. A semiconductor laser, with the power $\mathrm{P}=5 \mathrm{~mW}$ and the wavelength $\lambda=630 \mathrm{~nm}$, was used to perform the measure- 
ments. Taking into account unwanted diffraction and scattering effects, the real DE corresponding to the useful image was evaluated in the range of 70-75\%. A high DE allowed for realising the so-called "asymmetric hidden image" security effect (Fig. 4a). Considerable inhibition of symmetric mirror images for the $I_{+1}$ and $I_{-1}$ order diffraction helped place various original images in these diffraction orders avoiding overlapping. Formula (5) contains coefficients related to the relative brightness of dots in the original image to calculate CGHs. This option allows using a greyscale photo or image to calculate a hologram (Fig. 4b). An "asymmetric hidden image" (Fig. 4a) is one of the most complicated features of counterfeit, and checking it always requires a laser pointer and scattering screen, which is not convenient in some cases. The security effect calculated by (6) adds to the CGH phase function of the virtual spherical lens and makes the recovered image visible like through a real lens. Visually, this effect is very impressive and can be observed in the sunlight or other point light sources.

\section{CONCLUSION}

The present paper is devoted to the calculation and study of CGH recording parameters in the situation of their use in a complex structure of relief-phase protected holograms. A complex mathematical calculation and strict requirements for the parameters of optical recording make $\mathrm{CGH}$ elements difficult to counterfeit. The software for $\mathrm{CGH}$ calculation was created on the basis of the proposed improved ray-tracing algorithm. The created software for calculating of CGHs is completely compatible with the DifX system of recording of protective holograms and allows using CGHs of any shapes and sizes in the complex structure of a protective hologram. It should be noted that the number of visual and security effects implemented using CGH can be potentially greater than described. For example, protective effects to form an image in only certain predefined planes can be achieved, which might be useful in automatic authentication of security holograms.

\section{ACKNOWLEDGMENTS}

The present research has been partly supported by the National Research Programme of Latvia "Multifunctional Materials and Composites, Photonics and Nanotechnology (IMIS2)”.

\section{REFERENCES}

1. Murano, K., Shimobaba, T., Sugiyama, A., Takada, N., Kakue, T., Oikawa, M., and Ito, T. (2014). Fast computation of computer-generated holograms using Xeon Phi coprocessor. Computer Physics Communications, 185 (10), 2742-2757, DOI: 10.1016/j. cpc.2014.06.010.

2. Bulanovs, A., Tamanis, E., and Mihailova, I. (2011). Holographic recording device based on LCoS spatial light modulator. Latvian Journal of Phys. and Tech. Sciences, 48 (5), 60-68, DOI: 10.2478/v10047-011-0034-5. 
3. Bulanovs, A., Gerbreders, V., Kirilovs, G., and Teteris, J. (2011). Investigations of AsS-Se thin films for use as inorganic photoresist for digital image-matrix holography. Central European Journal of Physics, DOI: 10.2478/s11534-010-0133-6.

4. Firsov, An., Firsov, A., Loechel, B., Erko, A., Svintsov, A., and Zaitsev, S. (2014). Fabrication of digital rainbow holograms and 3-D imaging using SEM based e-beam lithography. Optics Express, 22 (23), 28756-28770, DOI: 10. 1364/0E. 22. 028756.

5. Bulanovs, A., and Gerbreders, S. (2013). Advanced concept for creation of security holograms. Latvian Journal of Phys. and Tech. Sciences, 50 (6), 61-70, DOI: 10.2478/ lpts-2013-0041.

6. InnoSol. (n.d.). Retrieved 17 April 2016, from www.difx-holo.com

7. Holoeye. (n. d.). Retrieved 17 April 2016, from www.holoeye.com

8. MicroChemicals. (n.d.). Retrieved 17 April 2016, from www.microchemicals.com

9. Bulanovs, A., Tamanis, E., and Kolbjonoks, V. (2013). The 'hidden image' effect in security holograms and its personalization by laser demetallization. Proc. SPIE 8776, Holography: Advances and Modern Trends III, 87760R, DOI:10.1117/12.2017135.

\title{
DATORA G̣ENERĒJOŠO HOLOGRAMMU IZMANTOŠANA DROŠĪBAS HOLOGRAMMU PIELIKUMOS.
}

\author{
A. Bulanovs, R. Bakanas
}

\section{Kopsavi $1 \mathrm{kums}$}

Rakstā ir apskatīta datora ǵenerējošo hologrammu izmantošana kā vienu no drošības pazīmēm reljefa-fāzes aizsardzības hologrammām. Parādīta datora generējošo hologrammu aprēḳina uzlabota metode, paralēlo staru interferences gadījumā. Izstrādāts programmnodrošinājums datora ǵenerējošo hologrammu daudzlīmeņu fāzes aprēḳinam, un to integrācija drošības hologrammu struktūrā. Aprēķinātās fāzes hologrammas mikrostruktūra tika ierakstīta uz fotorezista ar optiskās litogrāfijas palīdzību. Ierakstīto mikrostruktūru parametri tika pētīti ar atomu-spēka mikroskopijas un skenējošas elektroniskās mikroskopijas metožu palīdzību. Darba rezultāti parādīja datora ġenerējošo hologrāfisko elementu mikrostruktūru augstas drošības īpašības. Mūsuprāt, datora ǵenerējošo hologrāfisko elementu plaša izmantošana sarežğîto drošības hologrammu struktūrā ir perspektīva, jo l̦auj palielināt aizsardzības līmeni pret viltošanu.

16.05.2016. 